\title{
The effect of a herbal combination of primrose, gentian root, vervain, elder flowers, and sorrel on olfactory function in patients with a sinonasal olfactory dysfunction*
}

\author{
J. Reden, D. El-Hifnawi, T. Zahnert, T. Hummel
}

Smell \& Taste Clinic, Department of Otorhinolaryngology, University of Dresden Medical School, Dresden, Germany

\begin{abstract}
SUMMARY Olfactory dysfunction is a common symptom in patients with inflammation of the nasal mucosa. Among numerous drugs, so far only the use of steroids has been shown to have a positive effect on olfactory function. Therefore the aim of the present study was to investigate whether patients with sinonasal disease would benefit in terms of olfactory function from oral treatment with a herbal drug (combination of primrose, gentian root, vervain, elder flowers, and sorrel: Sinupret $\left.{ }^{\circledR}\right)$ which is commonly used in sinusitis. Olfactory function was tested using a standardised olfactory test kit ('sniffin' sticks'). The drug was applied in a double-blind fashion: after an initial therapy of 7 days of oral prednisolone for all participants with a sinonasal olfactory disease, participants were divided into a placeboand a verum-group; tests were performed before and after treatment over a 2 months period. Statistical analysis did not reveal any major differences in olfactory function in relation to treatment. Considering that its benefit for the inflammatory component of sinusitis has been shown, the herbal drug may exhibit positive effects on olfactory function in a different setting, e.g., when applied without preceding administration of prednisolone, or when used in patients with certain degrees of rhinosinusitis.
\end{abstract}

Key words: smell, therapy, olfactory loss, hyposmia

\section{INTRODUCTION}

Loss of olfactory function has a major impact on quality of life. It reduces the perception of flavour during eating and drinking, affects social behaviour and may result in dangerous situations, e.g. when spoiled food or smoke cannot be detected ${ }^{(1)}$. Causes for a reduced sense of smell are complex. The malfunction may be caused by a damage of the olfactory mucosa and neurons due to viral infections or head trauma. In addition, neurodegenerative diseases (e.g. Parkinson's or Alzheimer's disease) are typically combined with olfactory dysfunction (2).

However, in most cases, an inflammation of the mucosa is responsible for olfactory loss, such as in chronic or acute rhino-sinusitis ${ }^{(3)}$. In patients with rhinosinusitis, olfaction besides sneezing and headache - is one of the major symptoms. Up to now, for treatment of olfactory dysfunction in sinonasal disease only the benefit of orally applied steroids has been shown ${ }^{(4)}$. Unfortunately, apart from the positive effect on smell ability systemically given steroids produce a number of side effects that limit the usage of the medication, e.g. increase of blood pressure, diabetes mellitus, osteoporosis and central nervous irritations can be observed. Furthermore, the typical improvement after corticoid therapy is limited for the period of the treatment; the olfactory performance decreases within days to weeks when medication is stopped ${ }^{(5)}$.

Therefore, there is an urgent need of an effective and well tolerable alternative. In the present study, a herbal drug (a herbal combination of primrose, gentian root, vervain, elder flowers, and sorrel: Sinupret ${ }^{\circledR}$, Bionorica AG, Neumarkt, Germany) was tested on its effect on olfaction. Its safety and acceptance is known ${ }^{(6)}$, and a number of studies have proven its beneficial effect on sinusitis (e.g., ${ }^{(7,8)}$ ).

\section{PATIENTS AND METHODS}

Participants of this study were recruited from the Smell \& Taste clinic of the Department of Otorhinolaryngology at the University of Dresden Medical School. After a detailed interview all patients were examined thoroughly by an ENT-specialist, including endoscopy of the nasal cavity. The level of polyposis was determined by the polyposis-score ${ }^{(9)}$, 
ranging from 0 (no polyps) to 3 (total blockage of the nasal cavity, considering the more affected side). If history and clinical findings suggested a sinonasal cause for the olfactory disease patients were informed about intention and risks of the study, following the Declaration of Helsinki about ethics in studies on human beings.

Fifty-five patients participated in the first session ( 23 female, 32 male; mean age 53 years). After signing the consent form, patients were asked to estimate their olfactory ability (very good to very poor) and the degree of olfactory function was investigated.

\section{Olfactory testing}

Olfactory function was assessed by means of the 'Sniffin' Sticks' test kit, a validated psychophysical technique consisting of phenylethanol odour threshold testing, odour discrimination, and odour identification tests ${ }^{(10)}$. The results of the individual tests were summated to the so called TDI-score (with a maximum score of 48 points), which reliably indicates the degree of olfactory function. A score of 32 points or more represents normosmia, a score between 16 and 32 points stands for reduced olfactory function in terms of hyposmia, and a score of less than 16 points indicates functional anosmia ${ }^{(11)}$. All of these patients received the identical medication in the first step, i.e. $30 \mathrm{mg}$ Prednisolone daily for one week (see Figure 1 for a graphical display of the study design). A second session with similar tests was performed 1 week later. Condition for the further participation in the study was an improvement of olfactory function by means of an increase of TDI-score of more than 3 points. If they did not fulfil this change they were excluded from the further study. From this point the remaining patients were divided into either the verum group $(n=16)$ or the placebo group $(n=20)$, receiving either the herbal drug or placebo orally thrice a day for 2 months in a double-blind manner. After this period, in a third session again the olfactory performance was tested. In order to observe a long-term effect, finally, after one month of no treatment, a last session took place. In addition, patients were grouped regarding the grade of polyposis, considering the more affected side. Accordingly, 7 (8) patients had no polyps, 10 (5) patients grade 1 and 3 (3) grade 2 in the placebo- (verum-) group. Polyposis grade 3, a total blockage of the nose was an exclusion criterion.

\section{Statistical analysis}

Statistical analyses were performed using SPSS (Statistical Packages for Social Sciences, Version 12.0; SPSS Inc., Chicago, IL, USA). T-Tests were used for investigating differences between groups. In addition, one-way analyses of variances (ANOVA) were used to study the relation between the TDI score and variables like smell ability (an-/hyp- or normosmia), ratings, and change of TDI-score in relation to therapy. The level of significance was set at 0.05 .

\section{RESULTS}

According to the above mentioned study design, after dropping out of 19 patients, 36 patients were finally included (17 female, 19 male; mean age 52 years). There were no differences between the groups regarding age, duration of sinonasal disease and smell impairment or the initial olfactory test results (Table 1).

Mean changes in TDI-score between first and second session (one week of prednisolone treatment) were highly significant for the placebo- and verum group (13.2 and 11.1 points, respectively; $\mathrm{p}<0.001$ ), without significant differences between groups (Figure 2). After 2 months of placebo- / verum-treatment a significant decrease of the test scores could be observed in both groups ( 8.4 points in the placebo group, and 6.8 points in the verum group), again without significant difference between groups. In the last session, after an additional month of no treatment, only minimal changes of the mean TDI-score occurred (1.1 and -0.7 in the placebo and the verum group, respectively).

Changes between baseline (first session) and each following session were significant in each group $(\mathrm{p}<0.05)$. However, there was no significant effect of the factor 'treatment' on the TDI-score $(\mathrm{F}[\mathrm{df}=2]=0.28 ; \mathrm{p}=0.67)$.

Regarding the influence of polyposis on olfactory function, a clear effect could be seen: the higher the grade of polyposis the lower the initial TDI-score ( $\mathrm{F}[\mathrm{df} 2] 4.3 ; \mathrm{p}=0.018)$; Figure 3$)$. Furthermore, changes of TDI-score in the course of the study varied depending on the degree of polyposis: the more the nose was blocked by polyps initially (i.e. the worse olfactory function) the higher was the positive effect of prednisolone regarding the TDI-score. This effect disappeared after 2 and 3 months after the end of prednisolone treatment.

\section{DISCUSSION}

In the present study, the influence of the herbal drug on sinonasal olfactory dysfunction was investigated. The results suggest that there is no therapeutic effect of the presently used dosage and duration of the verum on olfaction.

The reduction of the sense of smell can be a very incriminating situation, affecting quality of life of the concerned patients ${ }^{(1,12)}$. Unfortunately, these patients often receive no or poor information about their diagnosis and prognosis regarding their disease, because apparently knowledge of physicians about this issue is limited ${ }^{(13)}$. But even if the disease and its cause are identified, therapy remains difficult. So far, in representative studies on therapy of olfactory dysfunction, only the benefit of orally applied steroids could be demonstrated (14-15). The responsible mechanisms are thought to be the anti-inflammatory and anti-edematous effects. Unfortunately, measurable improvement of olfactory function does not remain but typically decreases after a certain period of time. Some patients report deterioration almost immediately after finishing the 
Table 1. Descriptive statistics of baseline data from all participants, separately for the verum and the placebo group.

\begin{tabular}{|c|c|c|c|c|c|c|c|}
\hline & & & & & \multicolumn{3}{|c|}{ paired t-Test } \\
\hline & Group & $\mathrm{n}$ & Mean & $\mathrm{SD}$ & $\mathrm{T}$ & $\mathrm{df}$ & Significance \\
\hline \multirow[t]{2}{*}{ age (years) } & Placebo & 20 & $53(34-67)$ & 9.3 & \multirow{2}{*}{0.513} & \multirow{2}{*}{34.0} & \multirow{2}{*}{0.611} \\
\hline & Verum & 16 & $51.2(22-67)$ & 11.9 & & & \\
\hline \multirow{2}{*}{$\begin{array}{l}\text { sinusitis } \\
\text { since (years) }\end{array}$} & Placebo & 10 & $9.1(1-24)$ & 8.7 & \multirow{2}{*}{-0.475} & \multirow{2}{*}{21.0} & \multirow{2}{*}{0.640} \\
\hline & Verum & 13 & $11.1(3-35)$ & 10.7 & & & \\
\hline \multirow{2}{*}{$\begin{array}{l}\text { Olfactory } \\
\text { impairment } \\
\text { since (years) }\end{array}$} & Placebo & 20 & $9.5(1-30)$ & 9.1 & \multirow[t]{2}{*}{1.235} & \multirow[t]{2}{*}{29.9} & \multirow[t]{2}{*}{0.226} \\
\hline & Verum & 16 & $6.3(1-20)$ & 4.9 & & & \\
\hline \multirow[t]{2}{*}{ TDI (sum score) } & Placebo & 20 & 14.3 & 5.6 & \multirow{2}{*}{-1.205} & \multirow{2}{*}{24.9} & \multirow{2}{*}{0.240} \\
\hline & Verum & 16 & 17.3 & 8.5 & & & \\
\hline \multirow[t]{2}{*}{$\begin{array}{l}\text { Threshold } \\
\text { (dilution steps) }\end{array}$} & Placebo & 20 & 1.5 & 2.2 & \multirow[t]{2}{*}{-1.130} & \multirow[t]{2}{*}{34.0} & \multirow[t]{2}{*}{0.266} \\
\hline & Verum & 16 & 2.5 & 2.8 & & & \\
\hline \multirow{2}{*}{$\begin{array}{l}\text { Discrimination } \\
\text { (number } \\
\text { correctly } \\
\text { identified) }\end{array}$} & Placebo & 20 & 6.4 & 1.7 & \multirow[b]{2}{*}{-1.416} & \multirow[b]{2}{*}{23.3} & \multirow[b]{2}{*}{0.170} \\
\hline & Verum & 16 & 7.6 & 2.9 & & & \\
\hline \multirow[t]{2}{*}{$\begin{array}{l}\text { Identification } \\
\text { (number cor- } \\
\text { rectly identified) }\end{array}$} & Placebo & 10 & 6.4 & 2.8 & \multirow[t]{2}{*}{-0.699} & \multirow[t]{2}{*}{24.9} & \multirow[t]{2}{*}{0.491} \\
\hline & Verum & 13 & 7.2 & 4.2 & & & \\
\hline
\end{tabular}

$\mathrm{n}=$ number of subjects; $\mathrm{SD}=$ standard deviation; $\mathrm{SEM}=$ Standard error of mean; $\mathrm{T}=\mathrm{t}$-value; $\mathrm{df}=$ degrees of freedom.

steroid therapy within days, other investigators demonstrated a decrease within $2-5$ months ${ }^{(14,16)}$. Thus, an effective and safe long-term medication is not available up to now.

The herbal drug tested in this study is well established and the effectiveness on acute and chronic sinusitis was frequently demonstrated ${ }^{(7,8)}$. Both, mucolytic and anti-inflammatory properties ${ }^{(17-19)}$ seem to be responsible for the improvement of disorders related to the rhino-sinusitis. However, its positive impact on olfaction was only described in an unpublished investigation, where a significant improvement of olfactory function was observed after 2 weeks treatment of patients with acute and acute recurrent sinusitis ${ }^{(20)}$.

As far as we know, the most effective therapy for sinonasal olfactory disease is systemically administered prednisolone. Starting at the best possible level of olfaction that can be achieved by conservative treatment, we investigated whether subsequently applied herbal drug is able to inhibit or decelerate the expected decrease of olfactory function towards the pre-therapeutic state. The here used dosage and duration of therapy with the herbal drug did not show such an effect. Even though a direct comparison between prednisolone and the herbal drug is difficult with the present study design, it appears to be obvious that the herbal drug has a less intense potency on the olfactory component of sinonasal disease than prednisolone. In addition to the mentioned general antiinflammatory property prednisolone comprises some specific interaction that might explain its predominance. For example, the expression of a $\mathrm{Na}^{(+)} / \mathrm{K}^{(+)}$-ATPase in the olfactory mucosa is regulated by prednisolone ${ }^{(21)}$. This enzyme is involved in the modulation of the ionic concentration of the olfactory mucosal microenviroment ${ }^{(22)}$. Furthermore, prednisolone has a positive influence on the nitric oxide (NO) -metabolism in the olfactory mucosa ${ }^{(23)}$. NO is known to have antibacterial effects and stimulates the mucociliary transport system ${ }^{(24)}$. In addition, NO seems to play an important role in central processing and modulating of olfactory information ${ }^{(25)}$. Taken together, prednisolone produces a clear improvement of olfactory function via various pathways which cannot be sustained by the herbal drug.

In both groups, verum and placebo, there was a significant decrease of the TDI-score after finishing the prednisolone therapy. However, importantly, this decrease does not lead to the very low, pre-therapeutic level, but remains significantly higher than the initial TDI-score (mean 5.9 / 3.6 points; $\mathrm{p}>$ $0.001 / p=0.035$ for placebo / verum, respectively). In addition to the initial effect of prednisolone, another phenomenon could explain the long lasting improvement of olfactory func- 


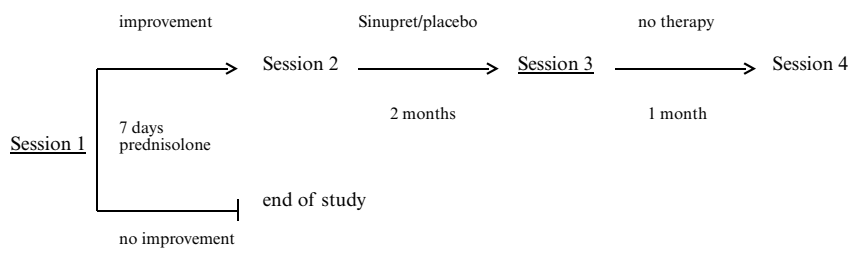

Figure 1. Graphical display of the study design.

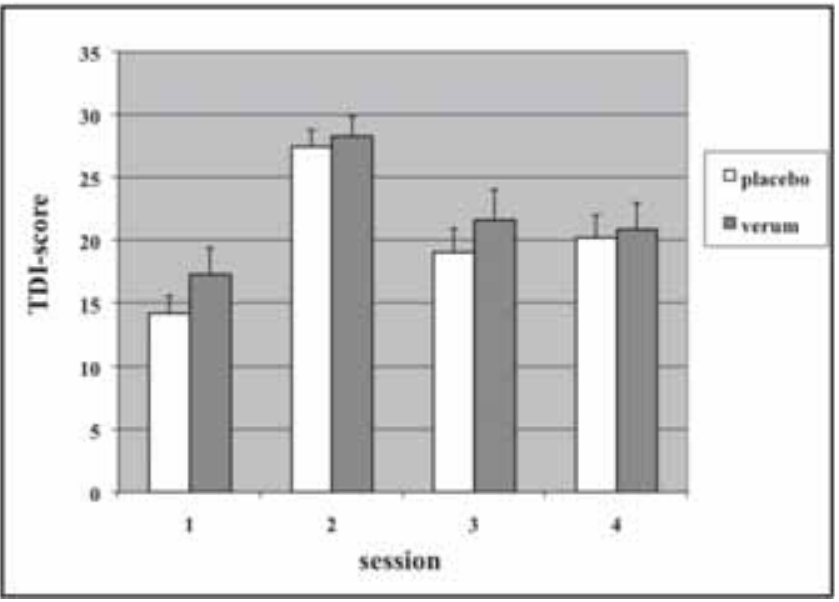

Figure 2. Change of olfactory function (TDI score) over time. Between session 1 and session 2 subjects received treatment with systemic prednisolone. After session 2, olfactory function decreased symmetrically for both, verum and placebo.

without preceding administration of prednisolone, or when used in patients with certain degrees of rhinosinusitis. In contrast, the well-known potency of prednisolone on olfactory impairment could be shown clearly, especially with regards to the presence of nasal polyps. Taken together, further studies are required since there is an urgent need for an effective and long lasting therapy to treat olfactory diseases.

\section{ACKNOWLEDGEMENTS}

This research was supported by Bionorica AG, Neumarkt, Germany

\section{REFERENCES}

1. Hummel T, Nordin S. Olfactory disorders and their consequences for quality of life. Acta Otolaryngol. 2005; 125: 116-121.

2. Welge-Lussen A. Ageing, neurodegeneration, and olfactory and gustatory loss. B-ENT. 2009; 5 Suppl 13: 129-132.

3. Damm M, Temmel A, Welge-Lussen A, et al. Olfactory dysfunctions. Epidemiology and therapy in Germany, Austria and Switzerland. Hno. 2004; 52: 112-120.

4. Landis BN, Hummel T, Lacroix JS. Basic and clinical aspects of olfaction. Adv Tech Stand Neurosurg. 2005; 30: 69-105.

5. Jafek BW, Moran DT, Eller PM, Rowley JC, 3rd, Jafek TB. Steroid-dependent anosmia. Arch Otolaryngol Head Neck Surg. 1987; 113: 547-549.

6. Ernst E, Sieder C, Maerz RW. Adverse drug reactions to herbal and synthetic expectorants. Int $\mathbf{J}$ Risk and Safety in Medicine. 1995; 7: 219-225.

7. Richstein A, Mann W. Treatment of chronic sinusitis with Sinupret. Ther Ggw 1980; 119: 1055-1060.

8. Neubauer N, Marz R. Placebo-controlled, randomized doubleblind clinical trial with Sinupret sugar coated tablets on the basis of a therapy with anti-biotics and decongestant nasal drops in acute sinusitis. Phytomedicine. 1994; 1: 177-181.

9. Lund VJ, Mackay IS. Staging in rhinosinusitus. Rhinology. 1993; 31: $183-184$

10. Hummel T, Sekinger B, Wolf SR, Pauli E, Kobal G. "Sniffin' sticks": olfactory performance assessed by the combined testing of odour identification, odour discrimination and olfactory threshold. Chem Senses. 1997; 22: 39-52. 


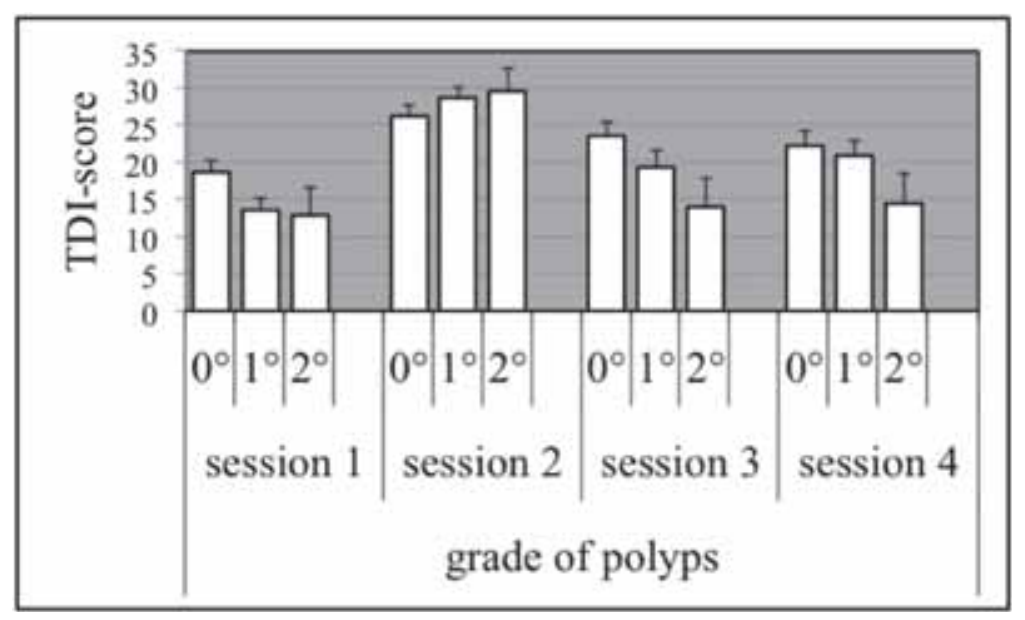

Figure 3. TDI-scores for each session subdivided into different degrees of nasal polyps. The more blockage of the nose the lower the TDI-score at the beginning and the stronger the improvement after prednisolone treatment.

11. Hummel T, Kobal G, Gudziol H, Mackay-Sim A. Normative data for the "Sniffin' Sticks" including tests of odour identification, odour discrimination, and olfactory thresholds: an upgrade based on a group of more than 3,000 subjects. Eur Arch Otorhinolaryngol. 2007; 264: 237-243.

12. Smeets MA, Veldhuizen MG, Galle S, et al. Sense of smell disorder and health-related quality of life. Rehabil Psychol. 2009; 54: 404-412.

13. Landis BN, Stow NW, Lacroix JS, Hugentobler M, Hummel T. Olfactory disorders: the patients' view. Rhinology. 2009; 47: 454-459.

14. Blomqvist EH, Lundblad L, Bergstedt H, Stjarne P. Placebocontrolled, randomized, double-blind study evaluating the efficacy of fluticasone propionate nasal spray for the treatment of patients with hyposmia/anosmia. Acta Otolaryngol. 2003; 123: 862-868.

15. Heilmann S, Huettenbrink KB, Hummel T. Local and systemic administration of corticosteroids in the treatment of olfactory loss. Am J Rhinol. 2004; 18: 29-33.

16. van Camp C, Clement PA. Results of oral steroid treatment in nasal polyposis. Rhinology. 1994; 32: 5-9.

17. Chibanguza G, Marz R, Sterner W. The effectiveness and toxicity of a plant secretolytic agent and its component drugs. Arzneimittelforschung. 1984; 34: 32-36.

18. Marz RW, Ismail C, Popp MA. Profile and effectiveness of a phytogenic combination preparation for treatment of sinusitis. Wien Med Wochenschr. 1999; 149: 202-208.

19. Ismail C. Pharmacology of Sinupret. Recent results on the rational for the Sinupret compound. Hno. 2005; 53 Suppl 1: S38-42.

20. Lopatin A, Kozlov V, Ismail C. Sinupret ${ }^{\circledR}$ zur Behandlung von akuter und wiederkehrender Rhinosinusitis: erste Ergebnisse einer doppelblinden, randomisierten, plazebo-kontrollierten multizentrischen klinischen Studie. nicht veröffentlichte Daten.

21. Fong KJ, Kern RC, Foster JD, Zhao JC, Pitovski DZ. Olfactory secretion and sodium, potassium-adenosine triphosphatase: regulation by corticosteroids. Laryngoscope. 1999; 109: 383-388.

22. Nishimura T, Teranishi S, Kawashima A, Ishimaru T, Miwa T, Furukawa M. Glucocorticoid enhances $\mathrm{Na}(+) / \mathrm{K}(+)$ ATPase mRNA expression in rat olfactory mucosa during regeneration: a possible mechanism for recovery from olfactory disturbance. Chem Senses. 2002; 27: 13-21.
23. Degano B, Tetu L, Serrano E, Didier A, Arnal JF. Nasal nitric oxide, the guardian of paranasal sinuses, is paradoxically increased by high doses of intravenous glucocorticoids. Allergy. 2005; 60: 1323-1326.

24. Alberty J, Stoll W, Rudack C. The effect of endogenous nitric oxide on mechanical ciliostimulation of human nasal mucosa. Clin Exp Allergy. 2006; 36: 1254-1259.

25. Wenisch S, Arnhold S. NADPH-Diaphorase Activity and NO Synthase Expression in the Olfactory Epithelium of the Bovine. Anat Histol Embryol. 2010; 39: 201-206.

26. Hummel T, Rissom K, Reden J, Hahner A, Weidenbecher M, Huttenbrink KB. Effects of olfactory training in patients with olfactory loss. Laryngoscope. 2009; 119: 496-499.

27. Soler ZM, Sauer DA, Mace J, Smith TL. Relationship between clinical measures and histopathologic findings in chronic rhinosinusitis. Otolaryngol Head Neck Surg. 2009; 141: 454-461.

28. Damm M, Jungehulsing M, Eckel HE, Schmidt M, Theissen P. Effects of systemic steroid treatment in chronic polypoid rhinosinusitis evaluated with magnetic resonance imaging. Otolaryngol Head Neck Surg. 1999; 120: 517-523.

Jens Reden, M.D.

Smell \& Taste Clinic

Department of Otorhinolaryngology

University of Dresden Medical School

Fetscherstr. 74

01307 Dresden

Germany

Tel: +49-351-458 4189

Fax: +49-351-458 4326

E-mail: jens.reden@uniklinikum-dresden.de 